\title{
Absolute bioavailability of imipramine: Influence of food
}

\section{Darrell R. Abernethy *, Marcia Divoll, David J. Greenblatt, Jerold S. Harmatz, and Richard I. Shader}

Division of Clinical Pharmacology, Departments of Psychiatry and Medicine,

Tufts University School of Medicine, and New England Medical Center Hospital, Boston, MA 02111, USA

Psychopharmacology (1984) 83:104-106

Due to printing errors, the senior author's name was unfortunately misspelled and Dr. Greenblatt was incorrectly identified as having moved to Houston. All authors' names should have been printed as shown above, and the asterisk at the bottom of the page should have referred only to Dr. Abernethy (senior author): 